\title{
An early start of West Nile virus seasonal transmission: the added value of One Heath surveillance in detecting early circulation and triggering timely response in Italy, June to July 2018
}

Flavia Riccardo ${ }^{1}$, Federica Monaco², Antonino Bella1, Giovanni Savini², Francesca Russo ${ }^{3}$, Roberto Cagarelli4, Michele Dottori5, Caterina Rizzo ${ }^{1,6}$, Giulietta Venturi ${ }^{1}$, Marco Di Luca ${ }^{1}$, Simonetta Pupella7, Letizia Lombardini ${ }^{8}$, Patrizio Pezzotti ${ }^{1}$, Patrizia Parodi9, Francesco Maraglino 9 , Alessandro Nanni Costa ${ }^{8}$, Giancarlo Maria Liumbruno7, Giovanni Rezza ${ }^{1}$, the working group ${ }^{10}$

1. Department of Infectious Diseases, National Institute of Health, Rome, Italy

2. Istituto Zooprofilattico Sperimentale Abruzzo e Molise, Teramo, Italy

3. Directorate of Prevention, Food Safety, and Veterinary Public Health, Veneto Region, Venice, Italy

4. Directorate of Prevention, Food Safety, and Veterinary Public Health, Emilia-Romagna Region, Bologna, Italy

5. Istituto Zooprofilattico Sperimentale Lombardia ed Emilia-Romagna, Sezione di Reggio Emilia, Italy

6. Bambino Gesù Children's Hospital, Rome, Italy

7. Italian National Blood Centre, National Institute of Health, Rome, Italy

8. Italian National Transplant Centre, National Institute of Health, Rome, Italy

9. Italian Ministry of Health, Rome, Italy

10. The members of the working group are listed at the end of the article

Correspondence: Flavia Riccardo (flavia.riccardo@iss.it)

Citation style for this article:

Riccardo Flavia, Monaco Federica, Bella Antonino, Savini Giovanni, Russo Francesca, Cagarelli Roberto, Dottori Michele, Rizzo Caterina, Venturi Giulietta, Di Luca Marco, Pupella Simonetta, Lombardini Letizia, Pezzotti Patrizio, Parodi Patrizia, Maraglino Francesco, Costa Alessandro Nanni, Liumbruno Giancarlo Maria, Rezza Giovanni, the working group. An early start of West Nile virus seasonal transmission: the added value of One Heath surveillance in detecting early circulation and triggering timely response in Italy, June to July 2018. Euro Surveill. 2018;23(32):pii=1800427. https://doi.org/10.2807/1560-7917.ES.2018.23.32.1800427

\author{
Article submitted on 02 Aug 2018 / accepted on o9 Aug 2018 / published on o9 Aug 2018
}

In Italy, the 2018 West Nile virus transmission season started early with a high number of cases reported. One-Health surveillance, within the Italian West Nile national preparedness and response plan, detected viral circulation 9 days before symptom-onset of the first confirmed human case; triggering timely implementation of blood and transplant safety measures. This is an example of how functional coordination allows health authorities to use early warning triggers from surveillance systems to implement preventive measures.

In 2018, West Nile virus (WNV) transmission in endemic Provinces in Italy began early with higher human case counts of confirmed infection compared with previous years. Here the start of the transmission season is described together with the response triggered by the integrated surveillance activities.

\section{Early West Nile virus transmission in Italy 2018}

In Italy, the earliest human cases of WNV infection are usually detected in July, with peaks in the number of cases in August-September (Figure 1). In 2018 however, the transmission season began earlier with the first detection of WNV in the Province of Rovigo (Veneto Region) [1] on 7 June from a pool of Culex mosquitoes; the first confirmed human case developed symptoms 9 days later in the same endemic Province (Figure 2). As of 1 August 2018, 52 confirmed cases of human WNV infection were notified in the Veneto and EmiliaRomagna Regions. These include 16 cases of West Nile Neuro-invasive Disease (WNND), 14 cases of West Nile fever (WNF) and 22 asymptomatic infections. Two WNND cases died (case-fatality rate (CFR) for WNND: $12.5 \%$ ). In all the affected Provinces, viral circulation was initially detected in mosquitoes and animals (equids and birds) and then later in humans, with no Provinces reporting only human cases (Figure 3). To date, only lineage 2 WNV has been identified in mosquitoes/animals.

Since 2009, the National Blood Centre (CNS) [2] and the National Transplant Centre (CNT) [3] have introduced nucleic acid testing (NAT) to detect and so prevent transmission of WNV infection through donated substances of human origin (SoHO). In addition to NAT, the CNT has introduced IgG/IgM testing to screen donors of tissues, cells and organs. Province-level (NUTS3) triggers for SoHO safety measures are confirmed viral detection in mosquito pools, or confirmed infection in animals or humans.

To date, in 2018, all SoHO safety measures have been activated as a result of animal/entomological triggers. 


\section{FIGURE 1}

Confirmed human cases of West Nile virus infection notified in Italy, June 2010-July 2018 (n = 415)

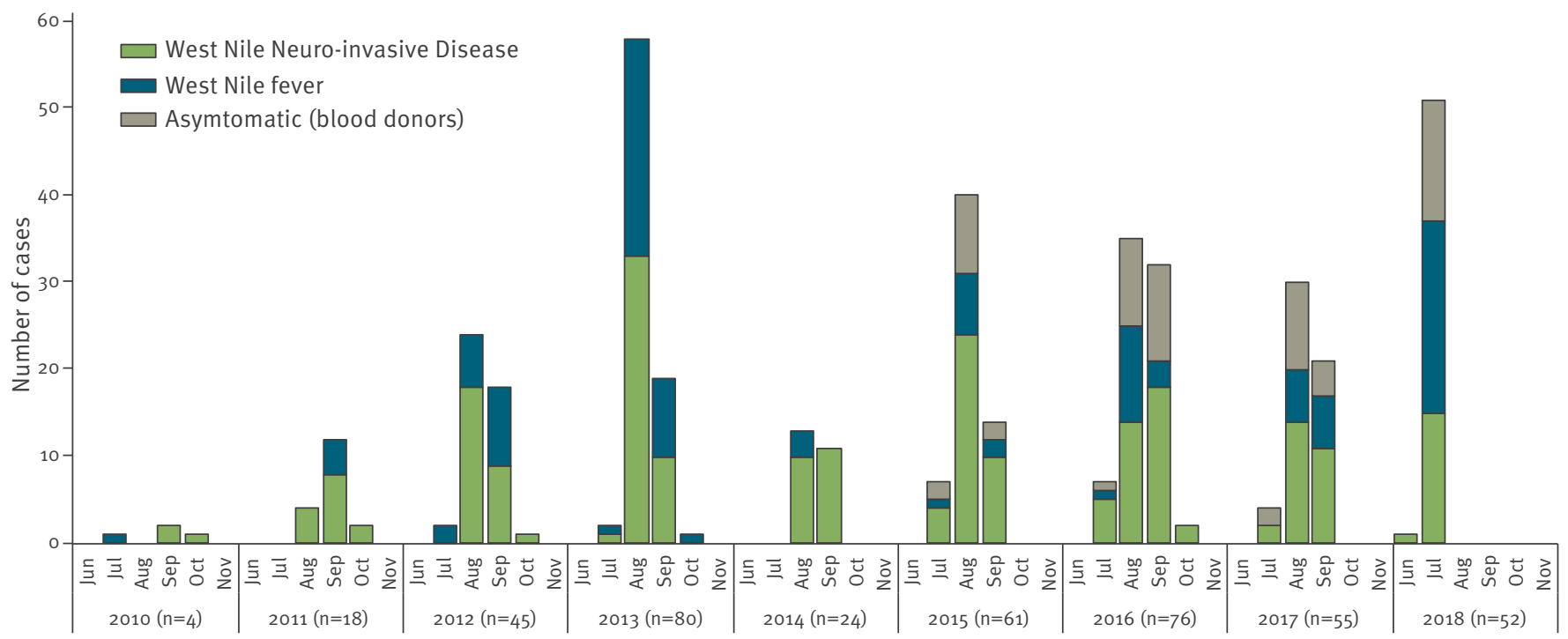

\section{FIGURE 2}

West Nile virus detection in Culex mosquitoes, birds, horses and humans, by date of detection or of symptom onset of West Nile fever, Italy, June-July 2018

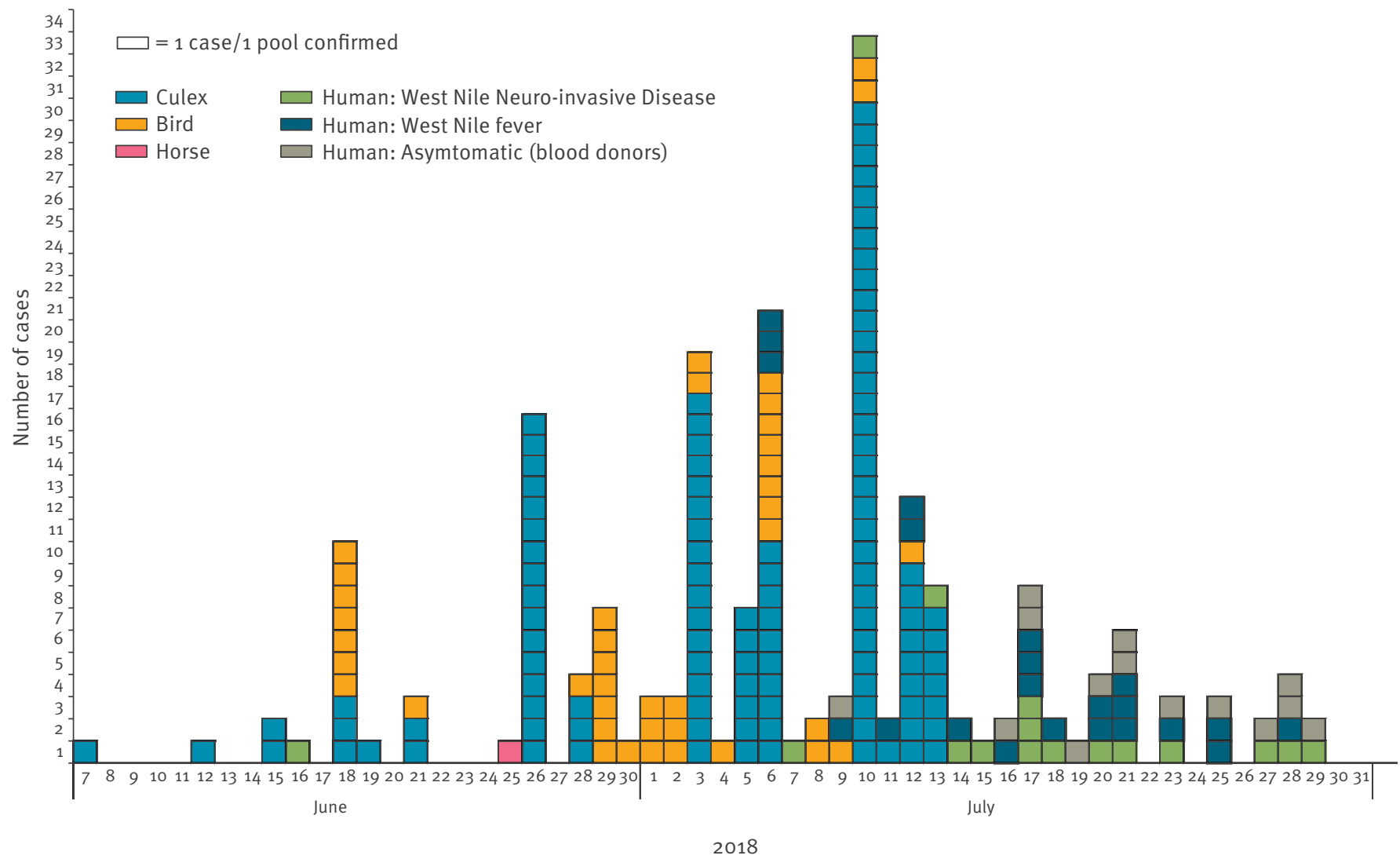

111 confirmed positive mosquito pools, 40 confirmed infections in birds, one confirmed infection in a horse and 52 confirmed human infections. 


\section{FIGURE 3}

Provinces where West Nile virus infection was detected in mosquitoes/animals/humans, Italy, June-July 2018 ( $\mathrm{n}=25$ provinces, of which 9 also reporting human infections)

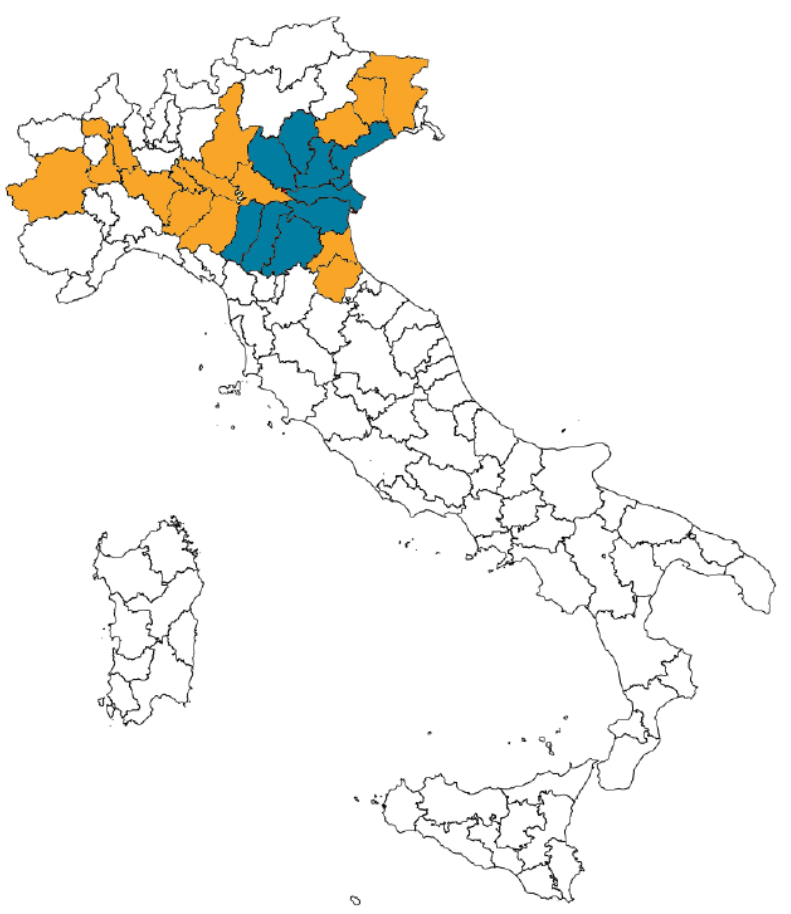

Provinces with demonstrated West Nile virus circulation in humans and in animals/vectors

Provinces with demonstrated West Nile virus circulation in animal/vectors

Provinces with demonstrated West Nile Virus circulation in humans

a No Provinces demonstrated West Nile virus circulation only in humans. To date human infections were reported only in Provinces where West Nile virus circulation in animals/vectors was also demonstrated.

As of 1 August 2018, CNS and CNT issued 14 official notes, in some instances addressing several Provinces at the same time. Vector control measures, as specified in the National preparedness and response plan [4] and further described in derived Regional plans and guidelines [5-8], were implemented at municipal level in all the affected Provinces.

\section{West Nile virus epidemiology and integrated surveillance and response in Italy}

Following the re-introduction of WNV in Italy in 2008 [9], it has caused cases of severe disease in humans every year. Only WNV lineage 1 was detected until 2011, when lineage 2 co-circulation was identified $[10,11]$. The disease is endemic in part of the country, mainly in Provinces located in a large valley in Northern Italy that hosts the basin of the largest Italian river (Po valley [12]). Sardinia, Sicily and the coastal Provinces of Lazio and Toscana are also endemic areas [4]. Transmission occurs mainly from bites of infected Culex mosquitoes but can also occur through the transfusion/transplant of contaminated SoHO [13].

In Italy, WNV is managed through an annually revised plan [4] aiming to reduce the risk of transmission to humans by detecting viral circulation early and triggering both vector-control and SoHO safety measures. The plan, coordinated by the Italian Ministry of Health, defines data flow processes to facilitate a rapid response among relevant stakeholders including: the Istituto Zooprofilattico Sperimentale dell'Abruzzo e Molise (IZSAM), the National Institute of Health (ISS-Rome) that hosts CNS and CNT and the National Reference Laboratory for Arboviruses as well as the National surveillance of human cases of WNV, Regional Authorities, Regional Reference Laboratories for Arboviruses, the network of the Istituti Zooprofilattici Sperimentali and Local Health Units and Municipalities. Thanks to this plan, communication exchange between human-animal and entomological surveillance actors and other health authorities has been strengthened.

The plan also defines the National integrated human, animal and entomological surveillance (One Health Surveillance [14]) which is intensified at provincial level on the basis of seasonality and local epidemiology [4]. Since the first human outbreak of WNV in Italy, increased awareness of the disease has enhanced case detection. Combined with improved surveillance, this has led to increased reporting of WNF cases, alongside WNND cases and, since 2015, to the detection of asymptomatic WNV infections among blood donors.

\section{Conclusion}

This year WNV transmission began earlier and with higher human case counts than in previous years in Italy. Compared with the same period 1971-2000, in June 2018 warmer temperatures and a higher cumulative rainfall were recorded [15]; possibly leading to more favourable conditions for mosquito survival and abundance and thus WNV transmission. At present, more human cases are expected until the end of the WNV transmission season. The situation is currently being monitored and preventive measures implemented as appropriate. Individual protection from mosquito bites remains the most important measure towards preventing WNV infection including the use of mosquito repellents, in accordance with the instructions indicated on the product label, wearing light coloured long-sleeved shirts and long trousers and sleeping or resting in screened or air-conditioned rooms [16].

In 2018, early WNV transmission has been also observed in other countries in South and South Eastern Europe [17]. In recent years changing patterns of transmission are being reported for several vector-borne diseases in Europe $[18,19]$ and climate change has been 
implicated as a contributing factor [20]. In the face of these changes, the One Health surveillance system in Italy managed to maintain its early warning function and, as a consequence, to date during 2018, all SoHO safety measures were enforced before the first human case was reported in each affected Province. This surveillance system, whose economic return was demonstrated in Italian endemic areas [21], is providing early warning signals and those are being acted upon in a timely fashion by implementing preventive measures.

\section{Working group}

The Working Group: C. Cenci, O. Bessi (Ministry of Health, Italy); V. Morabito (National Transplant Centre, Istituto Superiore di Sanità, ISS, Italy); G. Marano, I. Pati (National Blood Centre, Istituto Superiore di Sanità, ISS, Italy);C. Fortuna, M.E Remoli, R. Romi, F. Severini,, D. Boccolini, L. Toma, (Infectious Disease Department, Istituto Superiore di Sanità, ISS, Italy); M.C. Re (University of Bologna, Bologna, Italy); P. Angelini, A. Mattivi, C. Gualanduzzi (Regional Health Authority of Emilia Romagna, Bologna, Italy); F. Zanella, (Prevention and Public Health Unit, Directorate of Prevention, Food Safety, and Veterinary Public Health, Veneto Region, Venice, Italy); M. Claus (School of Specialization in Hygiene, Preventive Medicine and Public Health, University of Padua, Italy); P. Calistri, F. Iapaolo, M. Goffredo, G. Mancini (IZSAM); G. Capelli, F. Montarsi (IZSVE); M. Tamba (IZSLER); C. Casalone (IZSPLV).

\section{Acknowledgements}

The authors would like to acknowledge the following people involved in various aspects of West Nile Virus surveillance in the affected Regions: G. Mattei, M. Calzolari, P. Bonilauri, A. Mattivi, G. Rossini, C. Vocale, P. Gaibani, A. Lombardini

\section{Conflict of interest}

None declared

\section{Authors' contributions}

FIR; FM; $A B$ and $G S$ analysed the data, wrote the manuscript. $\mathrm{GR}, \mathrm{GML}, \mathrm{ANC}$ and FM coordinated the preparation of the manuscript and revised the content. GV, MDL, CR, SP, LL and $\mathrm{PaPe}$ contributed to the writing of the publication, gathered data and reviewed the final manuscript. FrR, RC, MD, PaPa and reviewed the final manuscript and, together with all the members of the working group, collected verified and provided data. All authors read and approved the manuscript.

\section{References}

1. West Nile and Usutu Virus Surveillance - Weekly bulletin, 27 June 2018 Italian. Available from: http://www.epicentro.iss. it/problemi/westNile/bollettino/Bollettino\%20WND_n.1\%20 28.06.2018.pdf

2. Italian National Blood Centre (CNS). Circolare Prot. n. 1251. CNS.2018 Indicazioni per la sorveglianza e la prevenzione dell'infezione da West Nile Virus mediante la trasfusione di emocomponenti labili nella stagione estivo-autunnale 2018. [Guidance for the surveillance and prevention of transmission of West Nile Virus through the transfusion of labile haemocomponents in the summer-autumn season 2018]. Rome: CNS, ISS; 6 Jun 2018. Italian. Available from: http://www. centronazionalesangue.it/sites/default/files/prot.\%201355\%20
CNT\%202018\%20WNV\%2olndicazioni\%20stagione $\% 20$ estivo\%20autunnale\%202018.pdf\#overlay-context=node/692

3. Italian National Transplant Centre (CNT). Circolare Prot. n. 1355. CNS.2018. Indicazioni per la sorveglianza e la prevenzione dell'infezione da West Nile Virus mediante trapianto d'organo tessuti e cellule nella stagione estivo-autunnale 2018. [Guidance for the surveillance and prevention of transmission of West Nile Virus through the transplant of organs, tissues and cells in the summer-autumn season 2018]. Rome: CNT, ISS; 6 Jun 2018. Italian. Available from: http://www. centronazionalesangue.it/sites/default/files/prot.\%201355\%20 CNT\%202018\%20WNV\%2olndicazioni\%20stagione\%20 estivo\%20autunnale \%202018.pdf\#overlay-context=node/692

4. Italian Ministry of Health. Piano nazionale integrato di sorveglianza e risposta ai virus West Nile e Usutu - 2018 [Italian National integrated surveillance and response plan to West Nile and Usutu viruses]. Rome: 27 Jun 2018. Italian. Available from: http://www.trovanorme.salute.gov.it/norme/ renderNormsanPdf?anno $=2018 \&$ codLeg $=65084 \&$ parte $=1 \% 20$ \&serie=null

5. Emilia Romagna Region. Piano sorveglianza arbovirosi 2018 [Arbovirus surveillance plan, 2018]. Italian. Available from: http://salute.regione.emilia-romagna.it/documentazione/ rapporti/Pianosorveglianzaarbovirosi2018.pdf/at download/ file/Piano\%20sorveglianza\%20arbovirosi\%202018.pdf

6. Regione Veneto. Piano Regionale di sorveglianza integrate e misure di lotta ai vettori, Anno 2018. [Regional Plan for integrated surveillance and vector control, 2018]. Italian. Available from: http://repository.regione.veneto.it/public/639c cd1eb ofa 4245d8432faf7bc83e7c.php?lang=it\&dl=true

7. Regione Emilia Romagna. Linee guida per lotta integrata alle zanzare vettrici del virus West Nile. Indicazioni tecniche alle AAUSSLL e ai Comuni [Guidelines for the integrated control of mosquito vectors of West Nile Virus. Technical guidance for local health unites and municipalities]. April 2016 Italian. Available from: http://www.zanzaratigreonline.it/LinkClick. aspx?link=Documenti\%2fLinee+guida+regionali+Culex West+Nile_2016.pdf\&tabid $=582 \&$ mid $=2214$

8. Regione Veneto. Linee operative per la sorveglianza delle arbovirosi in Regione Veneto. [Guidelines for the surveillance of arboviruses in the Veneto Region]. 2018 Italian. Available from:http://repository.regione.veneto.it/public/24e9495961d6 2a3795f49b94ceaoeaee.php?lang=it\&dl=true

9. Rizzo C, Napoli C, Venturi G, Pupella S, Lombardini L, Calistri P, et al. Italian WNV surveillance working group. West Nile virus transmission: results from the integrated surveillance system in Italy, 2008 to 2015. Euro Surveill. 2016;21(37):30340. https://doi.org/10.2807/1560-7917.ES.2016.21.37.30340 PMID: 27684046

10. Savini G, Monaco F, Calistri P, Lelli R. Phylogenetic analysis of West Nile virus isolated in Italy in 2008. Euro Surveill. 2008;13(48):19048. PMID: 19040827

11. Savini G, Capelli G, Monaco F, Polci A, Russo F, Di Gennaro $A$, et al. Evidence of West Nile virus lineage 2 circulation in Northern Italy. Vet Microbiol. 2012;158(3-4):267-73. https:// doi.org/10.1016/j.vetmic.2012.02.018 PMID: 22406344

12. United Nations Environment Programme, Division of Early Warning and Assessment (DEWA), Global Resource Information Database (GRID) - Europe.Po. Publications - Freshwater in Europe - Major European Watersheds - Po. Europe: DEWA/ GRID; 2008. Available from: https://web.archive.org/ web/20090801114726/http://www.grid.unep.ch/product/ publication/freshwater_europe/po.php

13. Velati C, Angelini P, Pupella S. State of the art: Vest Nile Virus circulation surveillance in Italy and transfusion risk early prevention methods. Transfus Clin Biol. 2017;24(3):172-5. https://doi.org/10.1016/j.tracli.2017.06.019 PMID: 28754422

14. Dente MG, Riccardo F, Nacca G, Ranghiasci A, Escadafal C, Gaayeb L, et al. Strengthening Preparedness for Arbovirus Infections in Mediterranean and Black Sea Countries: A Conceptual Framework to Assess Integrated Surveillance in the Context of the One Health Strategy. Int J Environ Res Public Health. 2018;15(3):489. https://doi.org/10.3390/ ijerph15030489 PMID: 29534445

15. Institute of Atmospheric Sciences and Climate (ISAC). Climate Monitoring for Italy. Bologna: ISAC; 2018. Available from: http://www.isac.cnr.it/climstor/climate_news.html

16. European Centre of Disease Prevention and Control (ECDC). Personal protective measures against mosquito bites. Stockholm: ECDC; 2018. Available from: https://ecdc. europa.eu/en/disease-vectors/prevention-and-control/ protective-measures-mosquitoes

17. European Centre of Disease Prevention and Control (ECDC). West Nile fever in Europe in 2018 - human cases compared to the previous season. Stockholm: ECDC; 27 Jul 2018. Available from: https://ecdc.europa.eu/en/publications-data/ 
west-nile-fever-europe-2018-human-cases-compared-previousseason-updated-27-july

18. Venturi G, Di Luca M, Fortuna C, Remoli ME, Riccardo F, Severini F, et al. Detection of a chikungunya outbreak in Central Italy, August to September 2017. Euro Surveill. 2017;22(39):17-00646. https://doi.org/10.2807/1560-7917. ES.2017.22.39.17-00646 PMID: 29019306

19. Escadafal C, Gaayeb L, Riccardo F, Pérez-Ramírez E, Picard $M$, Dente $M G$, et al. Risk of Zika virus transmission in the Euro-Mediterranean area and the added value of building preparedness to arboviral threats from a One Health perspective. BMC Public Health. 2016;16(1):1219. https://doi. org/10.1186/s12889-016-3831-1 PMID: 27914465

20. Semenza JC, Suk JE. Vector-borne diseases and climate change: a European perspective. FEMS Microbiol Lett. 2018;365(2):fnx244. https://doi.org/10.1093/femsle/fnX244 PMID: 29149298

21. Paternoster G, Babo Martins S, Mattivi A, Cagarelli R, Angelini $P$, Bellini R, et al. Economics of One Health: Costs and benefits of integrated West Nile virus surveillance in Emilia-Romagna. PLoS One. 2017;12(11):e0188156. https://doi.org/10.1371/ journal.pone.0188156 PMID: 29176851

\section{License and copyright}

This is an open-access article distributed under the terms of the Creative Commons Attribution (CC BY 4.0) Licence. You may share and adapt the material, but must give appropriate credit to the source, provide a link to the licence, and indicate if changes were made.

This article is copyright of the Author or their affiliated institutions, 2018. 